\title{
Development Reporting as a crumbling tower? Impact of Brown Envelope Journalism on journalistic practice in Zambia and Ghana
}

\author{
Twange Kasoma
}

\begin{abstract}
Development Reporting (DR) has long been considered the cornerstone of journalistic practice in Africa. The high prevalence of Brown Envelope Journalism (BEJ) - defined as a practice that involves news sources granting monetary incentives to journalists - is, however, posing a challenge to DR. BEJ has signaled a shift from a traditional model of DR, where journalists strived to report any legitimate development news to a public relations model where news is heavily influenced by source payments. Using Zambia and Ghana as case studies, this study provides insight into journalists' perspectives on DR and BEJ. Additionally, the study delves into the extenuating factors that perpetuate BEJ.
\end{abstract}

Key words: Africa, Brown Envelope Journalism, Development News, Development Reporting, Ghana, Journalistic Practice, Zambia.

\section{Introduction}

Journalistic practice in Africa in the $21^{\text {st }}$ century cannot be fully comprehended without reference to the dichotomy between BEJ and DR. From the onset of the post-independence era, many African nations laid emphasis on DR as the cornerstone of African journalism. DR posited the importance of the media in spearheading development. Historically, as Lederbogen (1992) notes, DR emphasised the importance of the media in the formation of national identities. Journalists such as Julius Nyerere and Jomo Kenyatta who were the first presidents of the independent states of Tanzania and Kenya exemplified this. Among the attributes of national identity that Nyerere and Kenyatta sought to preserve through the media were included language (specifically Swahili) and national dress.

Beyond the preservation of national identities, DR also involved a unique watchdog role that journalists played by visiting rural areas and reporting on development discourse. The postindependence African governments set up government-funded news agencies and/or information 
services to serve this purpose. In Zambia, for instance, Zambia News Agency (ZANA) was established in 1969 with a pool of journalists stationed in various districts countrywide to report

GMJ - AE Vol 3 (1)

on development. Topical development areas that ZANA reported on included new farming and irrigation techniques, education, health, etc. This way rural areas, which generally tend to be cut off from the mainstream in both availability and access to media, were integrated into the national economy.

In contemporary society, however, the efficacy of DR as the linchpin for African journalism has increasingly come under scrutiny due to the rampancy of BEJ. BEJ is defined as a practice that involves news sources granting monetary incentives to journalists or media outlets in order to get ample coverage. These monetary incentives are normally enclosed in brown envelopes - the idea being that since the envelopes are opaque, no one can tell that there is money in them. In Zambia, the brown envelopes are called ndalama yamatako while in Ghana they are referred to as soli. To shed more light on BEJ: if for example an organisation such as the Society for Family Health organises a press conference to launch their latest brand of mosquito nets the journalistic expectation is ndalama yamatako or soli. Absence of ndalama yamatako or soli amounts to no news or coverage, or mediocre coverage.

The amount of ndalama yamatako or soli depends on the type of event and a news source's financial disposition. On the low side, journalists get on average the equivalent of US\$7-\$10 per story assignment; a more generous offering would be in the region of US\$30-\$50 per story or assignment. Given that a journalist is, on average, assigned two stories a day the money they collect in brown envelopes by the end of the month outweighs their monthly salary. With journalists reaping substantially via BEJ, the question is how does the practice impact on DR, which traditionally is supposed to be devoid of brown envelopes? The purpose of this study, therefore, was to address this and other questions.

\section{Purpose of study}

As noted above this study attempts to analyse the impact that BEJ is having on DR. Zambia and Ghana were used as case studies. The study also analysed the rampancy of BEJ in Zambia and Ghana, and how journalists perceived the practice. Finally, the study also examined the professional portrait of journalists in Zambia and Ghana.

\section{Literature review and research questions}

A review of scholarly literature showed that the concepts of BEJ and DR are understudied. The few studies that have attempted to address the two concepts have only made mere reference to them while addressing other phenomena. For instance, studies that have made reference to BEJ have been those in the realm of ethics and journalistic professionalism. Studies that have made reference to DR have been those in the realm of national integration and development. Literature on BEJ and DR is reviewed below. 


\section{BEJ}

As noted above, scholarly literature on BEJ has been scarce. The few studies available have merely alluded to BEJ while addressing other phenomena. Mwesige’s 2004 study on

professionalism among Ugandan journalists is one such study. In this study, Mwesige found that the portrait of a Ugandan journalist was not so different from that of journalists in Western countries. He found remarkable similarities in age, gender and education. A point of departure, however, was that of BEJ. Unlike Western countries where the practice was foreign, in Uganda it had become part and parcel of journalistic practice. As Mwesige (2004:90) noted, BEJ had become internalised to the extent that some editors and media managers also condoned it: '.. at the government-owned Uganda Television ... organizations that want[ed] their events to appear on the news [we]re required to pay transport and other allowances to journalists.'

Working in the realm of ethics, Nyamnjoh (2001) also alluded to BEJ. From an ethical perspective, Nyamnjoh's preoccupation was with the negative consequences of BEJ. Nyamnjoh found that in Cameroon gombo (the euphemism for BEJ) led to the degrading of certain positions and encouraged the over-taxing and exploitation of equipment. This in turn resulted in poor output, engendering conflictual relations among colleagues, low levels of professionalism, and the loss of respect for evidence and balance. Other scholars that have addressed BEJ in the context of ethics are Kasoma (1996) and Ukpabi (2001). In their edited volumes, both Kasoma and Ukpabi raised the contentious issue of whether BEJ was tantamount to bribery and, if so, didn't it jeopardise journalistic objectivity on the African continent?

According to University of Oregon journalism students who part-took in a 2004 summer internship programme in Ghana, BEJ did compromise a journalist's objectivity. In an article by Leslie Steeves (2006), internship coordinator, the students shared their BEJ or soli experiences thus:

At the launching (of the Medium-Term Private Sector Development Strategy), I got to see President John Kufuor speak...Just for attending the event I received 60,000 cedis (about \$7) so that I would write a good story. Then _ (fellow reporter) went and got transcripts of the speeches and we wrote the stories off them. All the quotes from our article were taken directly from the transcript, one student wrote, implying that no effort was made to report critically and objectively.

Another student, in a more elaborative quote, wrote:

We went to a Ghana Telecom speech that was already over by the time we got there. The PR agent handed us a copy of the speech, and then gave us an envelope filled with money 'for transport.' ...We then made our way to an event celebrating women in science, after which we received more 'transportation money.' _ (fellow reporter) gave me half of the money and told me I could go home. She said she was going to buy a dress and that she 
would write the stories... I asked her if this was how she earned money. She said, 'Yes, don’t worry you will make lots of money' (Steeves, 2006).

Based on the above literature on BEJ, the current study posed the following questions:

GMJ - AE Vol 3 (1)

RQ1: How rampant is BEJ in Zambia and Ghana?

RQ2: What are the similarities and differences in the way journalists in Zambia and Ghana perceive BEJ?

RQ3: What extenuating factors perpetuate the practice?

\section{DR}

DR cannot be understood without specific reference to Hachten's (1981) development theory of the press, which calls for a partnership between the government and the media in the development process. In the context of development theory of the press, DR implies journalists' role in contributing positively to the improvement of peoples' quality of life both at the macro and micro levels. It entails not only reporting on the progress of development projects, but also taking leaders to task to ensure that promises they make vis-à-vis improving peoples’ welfare do not merely end up as lip service. Moreover, rather than just holding leaders accountable, DR also entails a kind of journalistic prowess that mobilises people to be proactive, particularly on matters relating to health, education, gender, etc.

Making DR proactive borrows from a theoretical framework that Lemert, Mitzman, Seither, Cook \& Hackett (1977) called Mobilizing Information (MI). MI simply means that when writing stories journalists should provide information that permits reader action to instigate development or social change. According to Lemert et al. (1977), MI is of three general types:

1. Locational MI, which involves providing information about the time and place of a potential activity

2. Identificational MI, which involves both an identification (such as a name and physical description) and some locational MI

3. Tactical MI, which involves the provision of explicit or implicit behavioral models, e.g. farming tips, disease preventive measures, etc.

To measure DR among Tanzanian journalists, Lederbogen (1992) asked them how satisfied they were with their contribution to the development of their country. He found only modest satisfaction. Kirat (1998) who studied Algerian journalists' perception of DR found that although conceptually the journalists recognised its efficacy, there was need for more news in that regard. One fifth of Algerian journalists defined development news as stories that helped raise the economic, cultural and political awareness of the people. About one sixth said development news was stories that helped people acquire more education and knowledge (Kirat, 1998). 
Building on scholarship in DR, the current study posed the following questions:

RQ4: What are the similarities and differences in the way journalists in Zambia and Ghana perceive DR?

RQ5: What are the perspectives of Zambian and Ghanaian journalists on the impact that BEJ has on DR?

Additionally, this study addressed the professional portrait of Zambian and Ghanaian journalists by posing the question:

RQ6: What are the similarities and differences in the professional portrait of Zambian and Ghanaian journalists?

\section{Methods}

This study was conducted over a two-year timeframe - during the summer of 2006 and 2008 respectively. In summer 2006, a questionnaire was distributed to a systematic sample of 300 journalists in Zambia and Ghana; 150 journalists were polled in each country. The study used Weaver and Wilhoit's (1991) definition of a journalist as any full and/or part-time employee actively involved in the newsgathering process (i.e. going out to collect stories, writing them and transmitting them). Although in Western countries this definition would exclude editors because an editor's job is considered supervisory, in the African context it is otherwise. Editors are increasingly taking on dual responsibilities, which include going out on assignments and writing stories, while also maintaining that supervisory role. In selecting media institutions for study, matters of political economy (precisely ownership and market share) and popularity were used. Based on these criteria, for each country, three types of media were selected (Table 1).

\section{Table 1: Media institutions studied}

\begin{tabular}{|l|l|l|}
\hline Media/Country & Zambia & Ghana \\
\hline State-owned corporation & $\begin{array}{l}\text { Zambia National } \\
\text { Broadcasting Corporation } \\
\text { (ZNBC) }\end{array}$ & $\begin{array}{l}\text { Ghana Broadcasting } \\
\text { Corporation (GBC) }\end{array}$ \\
\hline Privately-owned TV station & Muvi TV & $\begin{array}{l}\text { TV 3 } \\
\text { TV Africa*** }\end{array}$ \\
\hline
\end{tabular}




\begin{tabular}{|c|c|c|}
\hline Privately-owned radio station & $\begin{array}{l}\text { Radio Phoenix } \\
\text { Hot FM } \\
\text { Q FM } \\
\text { Hone FM }\end{array}$ & $\begin{array}{l}\text { Joy FM } \\
\text { Peace FM } \\
\text { Radio Univers } \\
\text { Citi FM }\end{array}$ \\
\hline State-owned newspaper & $\begin{array}{l}\text { Zambia Daily Mail } \\
\text { Times of Zambia }\end{array}$ & $\begin{array}{l}\text { Daily Graphic } \\
\text { Ghanaian Times }\end{array}$ \\
\hline Privately-owned newspaper & $\begin{array}{l}\text { The Post } \\
\text { Trend Setters } \\
\text { National Mirror** }\end{array}$ & $\begin{array}{l}\text { Chronicle } \\
\text { Statesman* } \\
\text { People \& Places } \\
\text { Financial Times } \\
\text { Accra Daily Mail }\end{array}$ \\
\hline State-owned news agency & $\begin{array}{l}\text { Zambia News and } \\
\text { Information Services } \\
\text { (ZANIS) }\end{array}$ & Ghana News Agency \\
\hline
\end{tabular}

* Never returned questionnaires

** Declined to participate in the study when contacted

*** Managing editor noted that he had no formally trained journalists that could participate in the study.

\section{Response rate}

Of the 300 questionnaires distributed 218 were returned. Of these 218, three were discarded because they were not completed. This left 215 (71.67 percent) usable questionnaires.

\section{Questionnaire and data analysis}

The 4-page questionnaire used in this study contained a series of open-ended questions and Likert-scale statements deemed appropriate to analyse the two concepts (BEJ and DR) being studied. To measure BEJ, some of the open-ended questions posed included:

(a) What is BEJ and how pronounced is it here?

(b) What is the largest amount of money that you have ever received from a news source?

(c) What kind of assignment were you covering when you received this money? Was it development-related? 
(d) How did receiving this money affect how you reported the story you were covering?

(e) How do you personally feel about news sources giving monetary incentives to journalists?

The questionnaire also contained Likert-type statements drawn from studies that alluded to BEJ from an ethical perspective. These statements, which included statements such as: 'it is alright for journalists to accept monetary incentives from news sources given the financial constraints they encounter in their work', were coded on a 5-point Likert scale. There was also provision of being interviewed on BEJ and how it affected a journalist's professionalism and his/her ability to

GMJ - AE Vol 3 (1)

report development news. Journalists who were interested in being interviewed had to indicate their contact information on the questionnaire.

As for DR, apart from open-ended questions that the journalists were asked on how they perceived DR and its efficacy, the measures that Johnstone, Slawski, \& Bowman (1976) identified for analysing the role of the media in society were also used. These were extended by context-specific clauses. The 14 statements that resulted from this endeavor were submitted to factor analysis in order to extract a quantifiable measure for DR. Three factors were yielded of which one was deemed appropriate for measuring DR in the Zambian and Ghanaian context (Table 2).

Table 2: DR factor

\begin{tabular}{|l|l|}
\hline Attribute & $\begin{array}{l}\text { Factor } \\
\text { loading }\end{array}$ \\
\hline $\begin{array}{l}\text { It is very important for the media to provide functional education in } \\
\text { literacy, disease prevention, new farming techniques, etc. for people } \\
\text { at the grassroots level. }\end{array}$ & .781 \\
\hline $\begin{array}{l}\text { It is very important for the media to give ordinary people a chance to } \\
\text { express themselves. }\end{array}$ & .723 \\
\hline $\begin{array}{l}\text { It is very important for the media to report corruption in government } \\
\text { and make leaders accountable to the people i.e. the watchdog } \\
\text { function. }\end{array}$ & .714 \\
\hline \begin{tabular}{l} 
It is very important for the media to set the public agenda. \\
\hline $\begin{array}{l}\text { It is very important for the media to promote solidarity and nation } \\
\text { building. }\end{array}$
\end{tabular} & .694 \\
\hline
\end{tabular}

Extraction Method: Principal Component Analysis 


\section{Rotation method: Varimax with Kaiser Normalisation}

The quantitative data were analysed using descriptive statistics and factor analysis. Charts and crosstabulations - specifically chi-square test of independence - were run. For statistical significance an alpha level of $\mathrm{p}<.05$ was required.

Beyond the quantitative methods, qualitative data were also collected. The qualitative methods used were in-depth interviews and participant observation. For in-depth interviews several stakeholders such as: journalists, editors, university professors, media foundations' executives and professional associations' presidents, were interviewed. The interview schedule and questions varied depending on which stakeholder was being interviewed. For example, interviews with journalists focused more on gaining BEJ insights from them (e.g. the ethicality

GMJ - AE Vol 3 (1)

of the practice, why it occurred, how it impacted their objectivity and reporting of development news). Interviews with professors took a more holistic approach. Professors were asked pertinent questions about what they, as educators, were doing to address BEJ and DR. A total of 40 interviews varying in length from one to two hours were conducted.

For the participant observation portion of the study, this researcher sat in the newsrooms and/or went out on assignments with reporters for about two weeks and observed them work. This procedure was mainly conducted at the Daily Graphic and the Ghanaian Times (Ghana) and ZNBC (Zambia). The time spent observing the journalists each day varied from an hour up to four hours. Snippets of participant observation were also done at: GBC (Ghana), Peace FM (Ghana), Radio Univers (Ghana), Statesman (Ghana), Accra Daily Mail (Ghana), Financial Times (Ghana), Chronicle (Ghana), People \& Places (Ghana), Zambia Daily Mail (Zambia), Times of Zambia (Zambia) and The Post (Zambia).

\section{Findings}

RQ1 asked how rampant BEJ was in Zambia and Ghana. This study found that the practice was commonplace. Almost all the journalists surveyed and interviewed attested to engaging in the practice. In Ghana, for instance, where during interviews journalists revealed that the practice is referred to as soli (the term itself being a shortcut for 'solidarity'), it was seen as a way of showcasing solidarity. Ndalama yamatako - the Zambian equivalent - translated into English meant 'money of the buttocks'. According to the Zambian journalists interviewed, although the English translation sounded vulgar, in the local context it simply meant: 'sitting allowance'. Ndalama yamatako, the journalists said, had a lot to do with their sitting in or attending workshops, meetings, press conferences, etc. in order to cover them.

RQ2 addressed similarities and differences in the way journalists in Zambia and Ghana perceived BEJ. The study found that both groups of journalists perceived the practice as customary was customary and part of media culture in their respective countries. The study also found that although the two groups of journalists had reservations about the impact that BEJ had on 
their objectivity, they did not necessarily see anything wrong with engaging in the practice. For example, an editor-in-chief for a Ghanaian state-owned corporation who agreed to be interviewed about BEJ vis-à-vis objectivity noted that he received US\$200 for doing an interview with "a highly placed political figure.” Asked whether this money affected his objectivity his response was: '[I'm] not sure. But often times money influences reporting.' However, the editor-inchief added that he did not see 'anything wrong' with his reporters accepting soli as long as it was 'not heavy.'

RQ3 asked about extenuating factors that perpetuated BEJ. A major factor, that this study found, was low pay. Of the journalists who were willing to reveal their monthly, the majority fell under the \$200-\$399 bracket. The highest paid, who were the editors, got around \$500 a month, while the lowest paid journalist made less than $\$ 100$ (Table 3). This study found a statistically

GMJ - AE Vol 3 (1)

significant interaction between pay and propensity to engage in BEJ (chi-square(6) = 19.74, $\mathrm{p}<.01)$. This finding was supported by qualitative data.

One Zambian journalist noted about receiving ndalama yamatako:

'We have no option looking at the salaries we get.' A Ghanaian reporter cheerfully said receiving soli is 'wonderful as it serves as a source of income.' Another Zambian journalist said: 'sometimes [ndalama yamatako] assists a reporter to go about the assignment smoothly without any financial hiccups. Sometimes media houses don't give enough funding for out of town assignments.' The downside to this, as one reporter noted is: 'it exerts unnecessary pressure on the journalist to meet certain expectations by the source.' Another added: 'I feel cheap as if the source is telling me how he would like me to go about my job.'

Table 3: Monthly salary

\begin{tabular}{|l|c|c|c|}
\hline Country/Salary & $\begin{array}{c}\text { Zambia } \\
(\mathbf{N}=\mathbf{1 0 7})\end{array}$ & $\begin{array}{c}\text { Ghana } \\
\mathbf{( N = 1 0 8 )}\end{array}$ & $\begin{array}{c}\text { TOTAL } \\
\mathbf{( N = 2 1 5 )}\end{array}$ \\
\hline Above $\$ 500$ & 19 & 5 & 24 \\
$(17.8 \%)$ & $(4.6 \%)$ & $(11.2 \%)$ \\
\hline$\$ 400$ to $\$ 500$ & 6 & 9 & $\mathbf{( 7 . 0 \% )}$ \\
\hline
\end{tabular}




\begin{tabular}{|l|c|c|c|}
\hline \$200 to \$399 & $\begin{array}{c}32 \\
(29.9 \%)\end{array}$ & $\begin{array}{c}35 \\
(32.4 \%)\end{array}$ & $\begin{array}{c}67 \\
(31.2 \%)\end{array}$ \\
\hline \$100 to \$199 & 4 & 14 & 18 \\
& $(3.7 \%)$ & $(13 \%)$ & 7 \\
\hline Below \$100 & 2 & 5 & $(3.3 \%)$ \\
\hline No response & $(1.9 \%)$ & $(4.6 \%)$ & 84 \\
& $(41.1 \%)$ & $(37 \%)$ & $(39 \%)$ \\
\hline
\end{tabular}

GMJ - AE Vol 3 (1)

Apart from pay, other variables tested to see if they were extenuating factors perpetuating BEJ included: age, gender, level of education, type of medium a journalist worked for and job title. These were submitted to a chi-square test of independence. No statistically significant results were found on age, gender, and type of medium a journalist worked for. However, level of education showed a statistically significant result (chi-square $(5)=13.04, p<.05$ ). Interestingly, the study found that the more educated a journalist was the more likely they were to engage in BEJ. For example, of the six journalists (all of whom happened to be Ghanaian) who had a masters degree, five responded affirmatively to receiving soli. Conversely, of the seven journalists with high school certificates - all of whom were Zambian - only one admitted to engaging in BEJ.

Moving to DR, RQ4 asked what similarities and differences existed in the way journalists in Zambia and Ghana perceived DR. The study found that although both groups of journalists appreciated the importance of DR, they also admitted not to doing enough in that realm. They addressed the reason for this mediocrity in RQ5, which asked: What are the perspectives of Zambian and Ghanaian journalists on the impact that BEJ has on DR? The two groups of journalists noted that since DR generally tended to be devoid of brown envelopes, they found themselves drawn to reporting the type of news that attracted brown envelopes. The study found that most such news in Zambia tended to be political e.g. rallies and politicians delivering speeches, whereas in Ghana it was a mix of political and business. In both countries, the study found that politicians were the main culprits when it came to handing out brown envelopes. The journalists interviewed indicated that they were aware that accepting such monies from politicians affected their objectivity. 
For example, a female reporter working for ZANIS noted that when covering a political campaign in Zambia by one of the political parties that was contesting the 2006 elections, she was paid K500,000 (about US\$125). She pointed out that: 'of course it affected my objectivity.' Asked to give an example of how his objectivity was affected by accepting ndalama yamatako, a journalist from the Times of Zambia said: 'It naturally made me want to write a story slanting on supporting the source.' He further explained: 'The trend has an inevitable influence on the reporter where they feel remorse not to write in the interest of the source.'

The study also found that while Zambian journalists were forthcoming about BEJ affecting their objectivity, their Ghanaian counterparts simply inferred it in their responses as illustrated in the interview transcript below:

A male reporter for a private radio station who received 200,000 cedis (about US\$20) at a press conference by a mining company said that receiving soli from news sources 'helps relieve the journalist of financial difficulties but should not in any way affect how the journalist reports. But it is also true that taking money from a news source makes it difficult to write against them.'

GMJ - AE Vol 3 (1)

A female reporter for a privately-owned newspaper noted that she was paid 300,000 cedis (about US\$30) to do an investigative piece 'in which the news source allegedly suspected foul play in the activities of an organization.' She further noted that although it was 'not too good' for her to accept this money the news source insisted on paying for her 'transportation costs'.

Another reporter working for a private radio station reported that she was given 'about $\$ 50$ for a product launch.' Commenting on how she personally felt about receiving such money she noted: 'I don’t particularly like it, but it is part of the "media culture” and rejecting it can be misconstrued as being offensive.'

The final research question delved into the professional portrait of Zambian and Ghanaian journalists. The study found that the two groups of journalists were similar in a number of regards. A typical journalist working in the two countries was a young, single man in his mid-tolate twenties with a college diploma. Zambian journalists, however, tended to be slightly younger than their Ghanaian counterparts. The youngest reported age for a Zambian journalist was 19 compared to 21 in Ghana. Of the surveyed journalists none in Zambia reported being past age 50. In comparison, six respondents in Ghana indicated that they were over 50, with the oldest being 56.

The study also found that having older journalists said something about the retention rate of journalists in Ghana compared to Zambia. Past the 30s, as in-depth interviews revealed, particularly in Zambia, there was a high defection rate from journalism to careers in public 
relations, advertising and politics. Two former journalists now working as public relations officers for private firms in Lusaka gave similar reasons for leaving journalism: 'It's a profession where if you are looking for money you don't become a journalist because there is no money there. All you find are the same things, you're bribed, there are monetary incentives ... you're being exploited, you're just being used for other people to climb the political ladder. Your integrity is at stake.'

\section{Discussion and conclusion}

The results of this study indicated that the rampancy of BEJ in Zambia and Ghana is translating into consumers being shortchanged on their development news needs. News journalism is increasingly taking on a public relations function where news paid for by sources is the one that is finding its way in the media. Development-related topics that seldom attract monetary incentives are being shunned and this is worrisome. In Ghana, for example, although this researcher found that the high prevalence of malaria made for worthwhile development news, the topic was hardly covered. Part of the reason why malaria prevalence was quite high in Ghana could be attributed to flooded gutters that ran parallel to streets and roads and provided a perfect breeding ground for mosquitoes. No reporter however reported on this. Conversely in Zambia, where the prevalence of HIV/AIDS is pretty high, and at any given time there are any number of myths going round about how to get cured from AIDS, stories debunking those myths were lacking. Those myths ranged from sleeping with young virgin girls to incest as a way to rid

GMJ - AE Vol 3 (1)

oneself of AIDS. People believed in these myths, practiced them and continued to lead reckless lives thereby perpetuating the spread of HIV/AIDS.

Beyond HIV/AIDS, other development-related topics only found their way in the media if someone had offered brown envelopes. Discussing the problem of child labour from a Zambian perspective - although the problem was also prevalent in Ghana - University of Zambia (UNZA) lecturer, Elizabeth Chanda, noted this in an interview:

At one time we were running a project by ILO where they wanted the media to get involved in reporting issues of child labor... The journalists came to the workshop and immediately started to ask how much they were going to be paid to write such stories. ILO agreed to pay them a token for a specified period (two months) and believe you me for that period, journalists wrote a lot of stories on child labor. After that period ended the stories disappeared -- that is how serious the problem is.

Perhaps even more worrisome is the fact that in some cases, journalists will do anything for those brown envelopes. A source from the World Food Program (WFP) lamented that in some cases, journalists literally use force to ensure that they are paid for covering development news. The WFP source shared an incident that transpired at a workshop at one of the hotels in Lusaka, Zambia's capital city. Journalists had to be restrained from manhandling the visibly shaken WFP country director because they were not given brown envelopes at the end of the workshop. 
In as far as addressing the problem goes Chanda said BEJ was now being talked about more and more in the classroom. She also said that a course (at undergraduate level) had been developed in development communication at UNZA to equip students with what to look out for when covering development news. In Ghana, as Dr. Audrey Gadzekpo noted, efforts are being made to revisit the definition of DR in the classroom. Gadzekpo said the mediocrity that characterised DR in the Ghanaian context had to do with the reduction of the concept to covering the actions of public officials and what they are doing about development in rural communities: 'So the news [becomes] writing about some minister erecting a toilet or promising to erect a toilet in some community. That is development news...' She further noted that journalists would go to the village and cover an event for which the minister was invited and the story would comprise what the minister said. 'How can people learn about what is happening in that village through the speech of the minister?'

As noted in the findings, one of the major factors contributing to the high prevalence of BEJ, which is in turn affecting DR, is journalists' meagre pay. To put a journalist's monthly pay into perspective, the Jesuit Centre for Theological Reflection (JCTR), which is a catholic research, education and advocacy organisation that advocates for social justice has estimated the food basket for a family of six at about $\$ 356$ a month. This amount does not include expenses such as housing, water, electricity, fuel, transport, clothing, education, health care, recreation, etc. When these are factored in a journalist's monthly pay becomes a real concern in terms of how far it can stretch.

GMJ - AE Vol 3 (1)

Some media managers also attributed the high prevalence of BEJ to media economics. Founder and managing editor of Accra Daily Mail, Harruna Attah, who operates his newspaper from his home due to economical constraints, elaborated further on the media economics argument:

Advertising is difficult to come by. Corporate social responsibility has been misunderstood in this part of the world to mean digging a borehole for a deprived community, donating money to a hospital, or sponsoring a sporting activity... But a lot of the corporate entities that don't advertise in our papers ... don't realize that part of their responsibility to society is to let democracy grow ... by supporting newspapers through advertising.

\section{Study limitations}

As with any scholarly work this study has its limitations. Firstly, the initial data collection in Zambia was done during a period considered volatile with regard to BEJ and this could have had a bearing on the results of the study. The data collection coincided with the run-up to the country's 2006 general elections. During this period BEJ is said to be at its peak. Also, due to the fact that this researcher found the state-owned media in both Zambia and Ghana to be more receptive than the privately-owned media, participant observation was mostly conducted there. As noted earlier, in Ghana, the participant observation was mainly conducted at Daily Graphic and Ghanaian Times, while in Zambia it was at ZNBC. This, therefore, meant that the results of 
the participant observation are biased toward reflecting mainly what transpires in state-owned as opposed to privately-owned media.

\section{Areas for future research}

The area of community media is a viable one to look into. The mushrooming of community media (most of which are donor-funded) in rural areas in the two countries has its own dynamics. These media are normally operated by members of a given rural community without any journalistic training. Of course some get assistance from professional journalists when available, but this is rare. It would be interesting to find out how rampant BEJ is in community media and how those who work within these fragile media perceive the practice. Another area for future research is to broaden the scope of the current study to include other African countries and compare them.

\section{Author details}

Twange Kasoma is teaching at the Emory \& Henry College in Virginia, USA.

\section{References}

Attah, H. 2006-08-10. Managing Editor, Accra Daily Mail. Personal interview.

Chanda, E. 2007-11-03. Lecturer, Department of Mass Communication, University of Zambia. Personal interview.

GMJ - AE Vol 3 (1)

Gadzekpo, A. 2006-08-05. Acting Director, School of Communication Studies, University of Ghana. Personal interview.

Hachten, W. A. 1981. The world news prism: changing media of international communication (3rd edition). Ames: IA: Iowa State University Press.

Johnstone, J. W. C., Slawski, E. J. \& Bowman, W. W. (1976). The news people: A sociological portrait of American journalists and their work. Urbana, IL: University of Illinois Press.

Kasoma, F. P. 1994 (Ed.) Journalism ethics in Africa. Nairobi, Kenya: African Council for Communication Education.

Kirat, M. 1998. Algerian journalists and their world. In: D. H. Weaver (Ed.) The global journalist: news people around the world (323-48). Cresskill, NJ: Hampton Press.

Lederbogen, U. T. Z. 1992. Watchdog or missionary? A portrait of African news people and their work: a case study in Tanzania. Frankfurt am Main, Germany: Peter Lang.

Lemert, J. B., Mitzman, B. N., Seither, M. A., Cook, R. H. \& Hackett, R. 1977. Journalists and mobilizing information. Journalism Quarterly, 54(4):721-726. 
Mwesige, P. G. 2004. Disseminators, advocates and watchdogs: a profile of Ugandan journalists in the new millennium. Journalism, 5(1): 69-96.

Nyamnjoh, F. B. 2001. Media ethics and professionalism in Cameroon. In: Ukpabi, C. (Ed.) Handbook on journalism ethics: African case studies, (65-86). Cape Town, SA: Creda Communications.

Steeves, L. 2006. Experiencing international communication: an internship program in Ghana, West Africa. Journalism \& mass communication educator.

Ukpabi, C. 2001. (Ed.). A handbook on journalism ethics: African case studies. Windhoek: Media Institute of Southern Africa.

Weaver, D. H. \& Wilhoit, G. C. 1991. The American journalist: a portrait of U.S. news people and their work. Bloomington, IN: Indiana University Press. 